\title{
A Maximum Power Point Tracking Algorithm for Photovoltaic Systems under Partially Shaded Conditions ${ }^{1}$ Algoritmo de seguimiento de máxima potencia para sistemas fotovoltaicos bajo condiciones de sombras parciales ${ }^{2}$
}

\author{
John Archila Valderrama ${ }^{3}$ \\ María Mantilla Villalobos 4 \\ Jaime Barrero Pérez \\ Johann Petit Suárez ${ }^{6}$ \\ Gabriel Ordóñez Plata
}

doi:10.11144/Javeriana.jyu20-2.mppt

How to cite this article:

J. Archila Valderrama, M. Mantilla Villalobos, J. Barrero Pérez, J. Petit Suárez, and G. Ordóñez Plata, "A maximum power point tracking algorithm for photovoltaic systems under partially shaded conditions," Ing. Univ., vol. 20, no. 2, pp. 391-409, 2016. http://dx.doi.org/10.11144/Javeriana.iyu20-2.mppt

\footnotetext{
' Submitted on: May $8^{\text {th }}, 2015$. Accepted on: February 15 $5^{\text {th }}, 2016$. Developed by the research groups Grupo de Investigación en Sistemas de Energía Eléctrica (GISEL) and Grupo de Investigación en Control, Electrónica, Modelado y Simulación (CEMOS) of Universidad Industrial de Santander, Bucaramanga, Colombia.

${ }^{2}$ Fecha de recepción: 8 de mayo de 2015. Fecha de aceptación: 15 de febrero de 2016. Desarrollado por el Grupo de Investigación en Sistemas de Energía Eléctrica (GISEL) y el Grupo de Investigación en Control, Electrónica, Modelado y Simulación (CEMOS) de la Universidad Industrial de Santander, Bucaramanga, Colombia.

${ }^{3}$ Ingeniero electrónico. Magister en Ingeniería Electrónica(c), Universidad Industrial de Santander, Bucaramanga, Colombia. E-mail: john.archila@correo.vis.edu.co

${ }^{4}$ Ingeniera electrónica. Magister en Ingeniería Electrónica. Doctora en Ingeniería(c). Profesora asistente, Universidad Industrial de Santander, Bucaramanga, Colombia. E-mail: marialem@uis.edu.co

${ }^{5}$ Ingeniero electricista. Magister en Potencia Eléctrica. Profesor titular, Universidad Industrial de Santander, Bucaramanga, Colombia. E-mail: jbarrero@uis.edu.co

${ }^{6}$ Ingeniero electricista. Magister en Potencia Eléctrica, Universidad Industrial de Santander, Bucaramanga, Colombia. Doctor en Ingeniería Eléctrica, Electrónica y Automática, Universidad Carlos III de Madrid, España. Profesor titular, Universidad Industrial de Santander, Colombia. E-mail: jfpetit@uis.edu.co

${ }^{7}$ Ingeniero electricista, Universidad Industrial de Santander, Bucaramanga, Colombia. Doctor en Ingeniería Industrial, Universidad Pontificia Comillas, España. Profesor titular laureado, Universidad Industrial de Santander, Colombia.

E-mail: gaby@uis.edu.co
} 


\section{Abstract}

This paper shows a modification of the traditional 'perturb and observe' algorithm used to the maximum power point tracking in photovoltaic systems. The proposal is justified by the need of algorithms to track the global maximum power point in solar panels connected in series under partially shaded conditions. The proposal tracks the global maximum power point avoiding the previous iterative search in local maximums. The algorithm performance is evaluated by simulations in the software PSIM and its behavior is compared with the traditional perturb and observe algorithm. The results show the outstanding performance of the modified algorithm in the tracking of the global maximum power point under different non uniform conditions of temperature and irradiance in the solar array.

\section{Keywords}

perturb and observe algorithm; DC-DC converters; photovoltaic systems; maximum power point tracking

\section{Resumen}

En este artículo se propone una modificación al algoritmo de perturbar y observar tradicional utilizado para el seguimiento del punto de máxima potencia en sistemas fotovoltaicos. El trabajo se encuentra justificado en la necesidad de disponer de algoritmos con los cuales encontrar el máximo global de potencia en paneles solares fotovoltaicos en conexión serie cuando están expuestos a condiciones de sombras parciales. El algoritmo propuesto realiza el seguimiento del máximo global de potencia y evita la búsqueda iterativa previa en máximos locales. El desempeño del algoritmo se evalúa por medio de simulaciones en el software PSIM y su funcionamiento se compara con el algoritmo de perturbar y observar tradicional, donde se evidencia la eficacia del algoritmo modificado en el seguimiento del máximo global bajo diferentes condiciones no uniformes de irradiancia y temperatura en el conjunto de paneles.

\section{Palabras clave}

algoritmo de perturbar y observar; convertidores DCDC; sistemas fotovoltaicos; seguimiento del punto de máxima potencia 


\section{Introduction}

Photovoltaic generators exhibit nonlinear characteristics between its power and output voltage, which in turn depend on the irradiance and temperature conditions to which they are exposed. Thus, it is of interest to ensure the generator's operation to the point at which it delivers maximum power in order to maximize the energy generated. For this, there are a variety of techniques used to track the Maximum Power Point Tracking (MPPT), which can be classified according to their complexity, the proper track of the global maximum power, the cost of implementation, the number of sensors, among others [1]-[7]. Among these techniques, Perturbation and Observation $(\mathrm{P} \& \mathrm{O})$ stands out for its low complexity implementation and good results in terms of efficiency under uniform irradiance conditions in the array of solar panels [8].

During the last few years, various changes to the $\mathrm{P} \& \mathrm{O}$ have been proposed seeking to improve their behavior under different operating conditions of the photovoltaic system. On one hand, in order to improve the dynamic response to sudden changes in irradiance and temperature, and reduce oscillations around the Maximum Power Point (MPP) at steady state, in [9]-[11] is proposed the Variable Step size modified $\mathrm{P} \& \mathrm{O}$ Algorithm, which can simultaneously improve the speed and efficiency of the MPPT. Other amendments are related to the inclusion of protective functions to the system load, where an additional control upon arrival at the maximum voltage and current supported by the load is included [12]. However, these changes in the $\mathrm{P} \& \mathrm{O}$ algorithm consider uniform irradiance and temperature conditions in the $\mathrm{PV}$ generator.

Figure 1a shows an example of the power-voltage curve of an array of photovoltaic modules in series connection under specific uniform conditions of temperature and irradiance, where the generator exhibits a single maximum power point. Nevertheless, when the irradiance and temperature conditions are not uniform in the arrangement of panels mainly due to possible partial shading conditions, the power-voltage curve may present several local points and a global maximum point. An example of the power-voltage curve of an arrangement of 3 solar 
panels in series connection under different levels of irradiance and temperature is shown in Figure $1 \mathrm{~b}$.

Figure 1. Power-voltage curves of an arrangement of 3 panels (reference KD240GH - 2PB KYOCERA) in series connection at: a) Uniform conditions of irradiance $800 \mathrm{~W} / \mathrm{m}^{2}$ and temperature $29^{\circ} \mathrm{C}$. b) Irradiance of $800 \mathrm{~W} / \mathrm{m}^{2}, 400 \mathrm{~W} / \mathrm{m}^{2}, 900 \mathrm{~W} / \mathrm{m}^{2}$ and temperatures of $27^{\circ} \mathrm{C}, 25^{\circ} \mathrm{C}$, and $29^{\circ} \mathrm{C}$, respectively

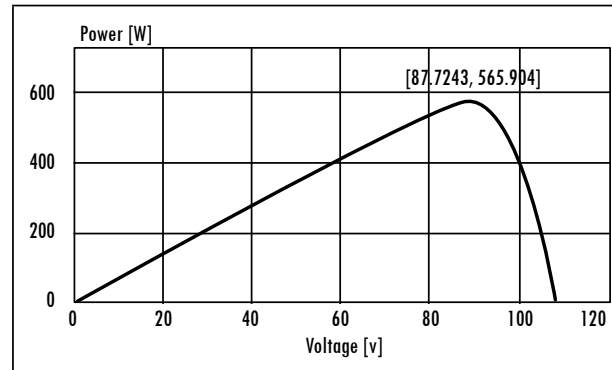

a)

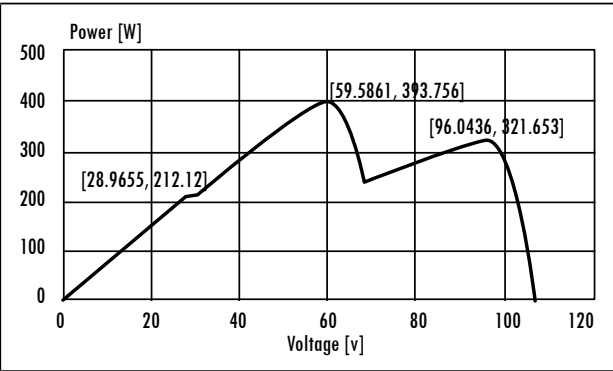

b)

Source: authors' own elaboration

When the photovoltaic array is under partial shading conditions, the traditional $\mathrm{P} \& \mathrm{O}$ algorithm can converge to a local maximum in steady state and oscillate around this point, thus reducing energy efficiency [13]. To counter this limitation, in [13] and [14] three methods, based on the P\&O technique, are proposed. These methods are used to find the global MPP under conditions of partial shading on panel arrays in series connection. The techniques require previous searches in local maxima through the traditional $\mathrm{P} \& \mathrm{O}$ technique before finding the global MPP, which can require multiple iterations resulting in large convergence times.

Accordingly, an algorithm of low computational cost based on the traditional $\mathrm{P} \& \mathrm{O}$ technique is proposed in this paper. This technique is used to track the global MPPT in arrays of solar panels connected in series under partial shading conditions. The proposed algorithm performs primarily a comparison process to find the area of the curve where the global MPPT is located. Subsequently, the traditional $\mathrm{P} \& \mathrm{O}$ technique is applied, taking a starting point in the predetermined region. In this way, the number of iterations needed to track the global maximum is reduced.

The paper is organized as follows. In the next section, the model of the equivalent photovoltaic system is introduced. In Section III, three MPPT algorithms 
are presented, including the proposed algorithm. Consequently, simulations results in the software PSIM for both the $\mathrm{P} \& \mathrm{O}$ traditional algorithm and the proposed algorithm are presented, in order to compare their performance under different conditions of irradiance and temperature. Finally the most important conclusions are highlighted.

\section{Photovoltaic System}

In Figure 2, the equivalent model of a grid-tied photovoltaic system is presented. In this schematic, it is considered a centralized architecture in which the solar panels are connected in series forming the photovoltaic generator. The resulting generator is connected to a DC-DC converter used to both adequate the DC signals and track the MPP. Then, this converter is connected to a capacitor, the power inverter, and a grid-tied filter.

Figure 2. Equivalent model of the photovoltaic system

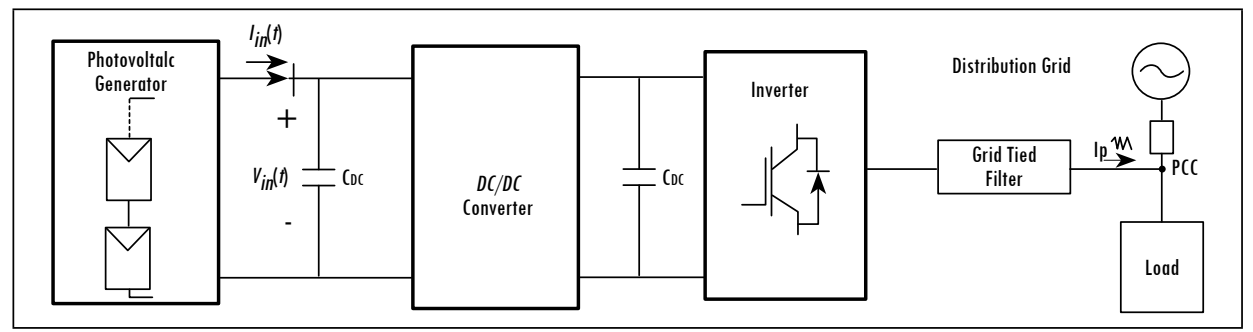

Source: authors' own elaboration

\subsection{Photovoltaic Generator}

Photovoltaic generators exhibit nonlinear relationships between the generated power and the output voltage, as previously presented in Figure 1. When the set of panels are exposed to uniform conditions of irradiance and temperature, the characteristic curves present a single MPP. This maximum varies depending on the radiation levels and temperatures to which the array is exposed.

In arrays of photovoltaic panels in series connection (considering panels with the same electrical characteristics and freewheeling diodes in parallel to each one), the power-voltage curves may have multiple local maxima and a single global maximum under non uniform irradiance and temperature conditions. The number of maxima (local and global) in the power-voltage curve corresponds to the number of subsets of solar panels with different conditions of irradiance and/or temperature. An example of 3 solar panels connected in series exposed to irradiance of $800 \mathrm{~W} / \mathrm{m}^{2}, 400 \mathrm{~W} / \mathrm{m}^{2}$ and $900 \mathrm{~W} / \mathrm{m}^{2}$ and temperatures of 
$27{ }^{\circ} \mathrm{C}, 25^{\circ} \mathrm{C}$, and $29{ }^{\circ} \mathrm{C}$, respectively, are shown in Figure $1 \mathrm{~b}$. As seen, the characteristic curve displays three maximum power points.

Figure 3 features another example of the power-voltage curve for 5 panels in series connection. In this case, two panels are exposed to irradiance of $1000 \mathrm{~W} / \mathrm{m}^{2}$ and $35^{\circ} \mathrm{C}$ and 3 panels to irradiance of $800 \mathrm{~W} / \mathrm{m}^{2}$ and $29^{\circ} \mathrm{C}$, so the power-voltage curve shows two maximum power points.

Figure 3. Power-voltage curve of an array of 5 panels reference KD240GH-2PB KYOCERA in series connection, 2 panels at irradiance of $1000 \mathrm{~W} / \mathrm{m}^{2}$ and temperature of $35^{\circ} \mathrm{C}$, and 3 panels at irradiance of $800 \mathrm{~W} / \mathrm{m}^{2}$ and temperature of $29^{\circ} \mathrm{C}$, respectively

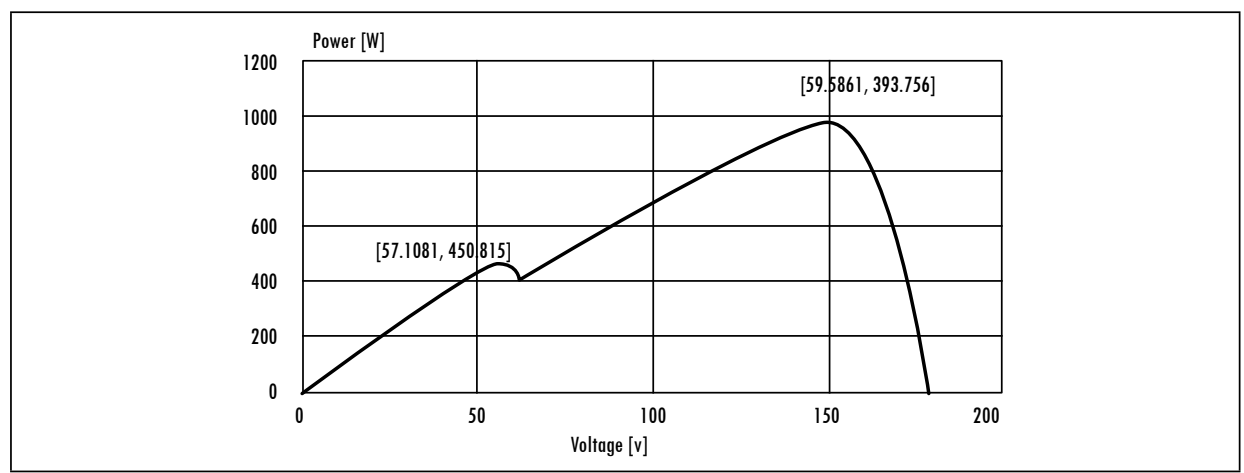

Source: authors' own elaboration

\subsection{DC/DC Converter}

The solar array is connected to a DC/DC converter (see Figure 4) used to perform the following functions:

- Ensure the operation of the PV generator at the maximum power point. This function is generally required in grid-tied photovoltaic systems.

- Adequate the DC voltage and current signals at the generator output to a certain level according to the application.

- In this paper a SEPIC (Single-Ended Primary-Inductor Converter) was selected, characterized by [15], [16]:

- Low ripple on the input current through the inductor L1 [17], [18].

- Non-inverted output voltage [17], [18].

- Buck-boost converter, which can operate under high or low levels of irradiance and temperature for different types of loads [19].

The SEPIC converter and its controller are observed in Figure 4. Firstly, the SEPIC controller performs the measurement of the instantaneous values of 
the voltage and current signals generated by the photovoltaic array. From these values, the MPPT algorithm adjusts the duty cycle of the SEPIC converter. Finally, a PWM (Pulse Width Modulation) module is used to generate the firing pulses of the electronic switch $Q_{1}$ by using the duty cycle.

Figure 4. Schematic of the SEPIC converter and the MPPT controller

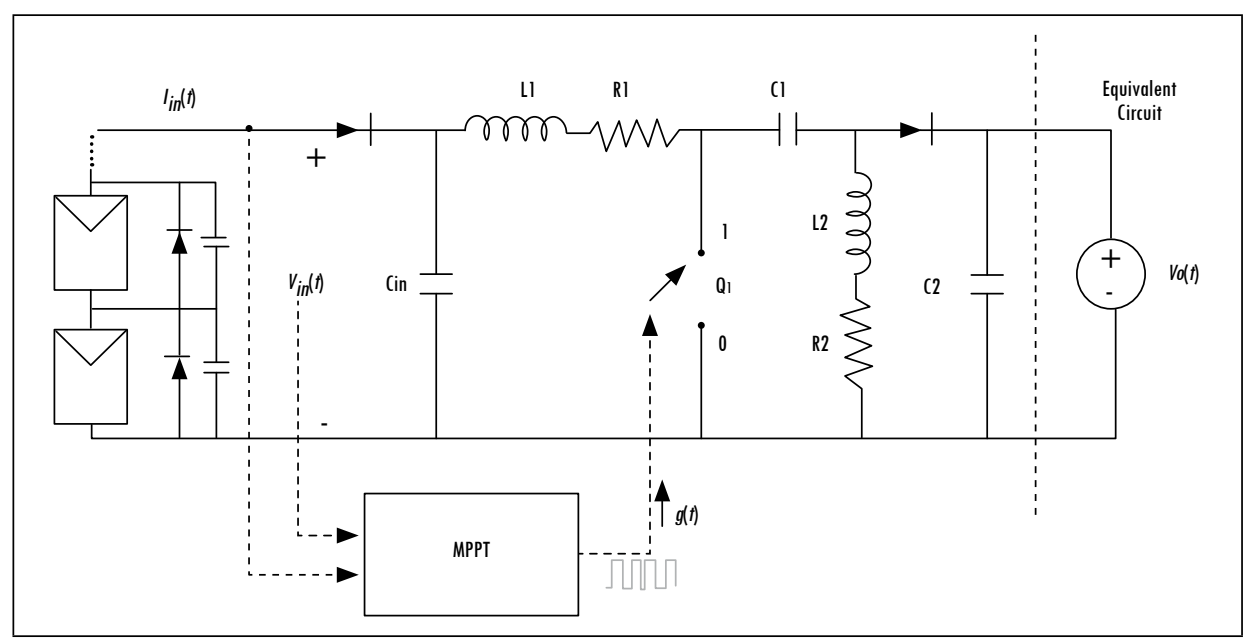

Source: authors' own elaboration

\subsection{Equivalent Circuit}

The $\mathrm{DC}$ side capacitor $\left(\mathrm{C}_{\mathrm{DC}}\right)$, the power inverter, the grid-tied filter, and the distribution network are represented by an independent voltage source $\left(V_{0}\right)$, as seen in Figure 4. This equivalent circuit is obtained considering that the large capacitance value of the DC side capacitor $\left(\mathrm{C}_{\mathrm{DC}}\right)$ allows decoupling the $\mathrm{DC}$ stage and the AC stage.

\section{Maximum Power Point Tracking Algorithms}

The MPPT algorithm is implemented in the SEPIC converter. This algorithm generates the firing pulses of the electronic device Q1 (see Figure 4) in order to ensure the tracking of the MPP under changes in the irradiance, temperature, partial shade, and operating conditions of the system.

\subsection{Perturbation and Observation Algorithm}

The $\mathrm{P} \& \mathrm{O}$ is one of the most widely used techniques because of its simple structure and easy implementation. In this algorithm the duty cycle $(D)$ of a power 
converter is periodically disturbed (increase or decrease). After each perturbation of the duty cycle, the actual value of the power $P(k)$ is compared with the power at the previous instant $P(k-1)$. If the perturbation results in an increase of the power, the next perturbation is made in the same direction, and if it leads to a decrease in power, the perturbation is performed in the opposite direction [20].

Figure 5 shows the flowchart corresponding to the operation of the $\mathrm{P} \& \mathrm{O}$ algorithm, where the variables $V(k), I(k)$, and $P(k)$ represent the voltage, current, and power at instant $\mathrm{k}$, respectively, at the output of the photovoltaic array. The algorithm makes comparisons regarding the changes in power $(d P)$ and voltage $(d V)$ in order to determine whether to increase or decrease the reference voltage $(V r)$ and modify the duty cycle $(D)$. Thus, the procedure is repeated until the system oscillates towards the MPP.

Figure 5. Flowchart of the $P \& 0$ technique

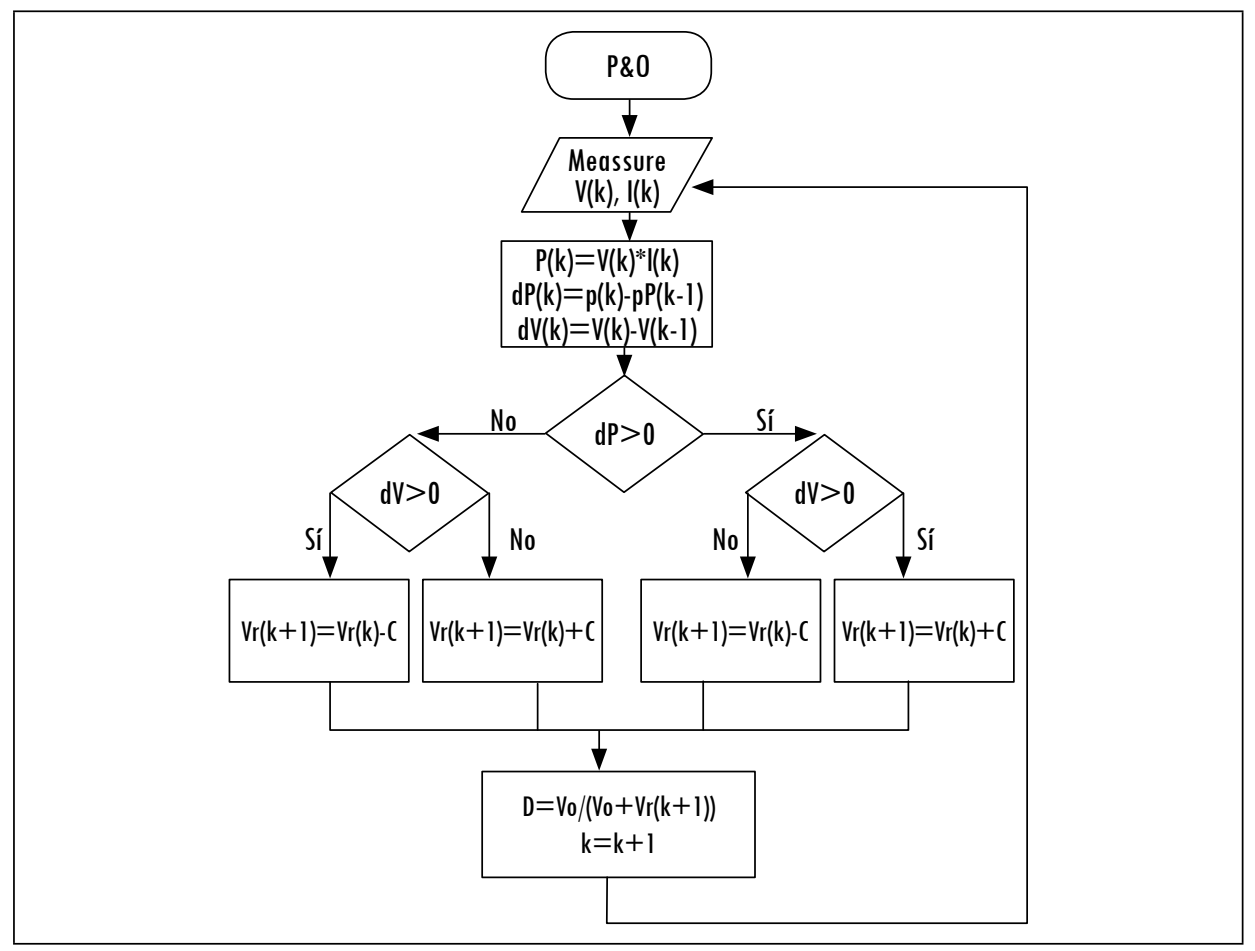

Source: authors' own elaboration 


\subsection{Perturb, Observe, and Check Algorithm (POC)}

Some authors have modified the traditional $\mathrm{P} \& \mathrm{O}$ technique in order to improve its performance under partial shading in photovoltaic arrays [13], [14]. In [14] the POC algorithm is proposed, which executes the traditional $\mathrm{P} \& \mathrm{O}$ algorithm in different regions of the curve where it is likely the occurrence of a maximum (both local and global maxima). Here, the algorithm determines the maximum points of the curve using the traditional $\mathrm{P} \& \mathrm{O}$ technique and subsequently, by a process of comparison, the algorithm converges to the global maximum point.

This strategy begins by taking as starting point a near-zero voltage reference $V r$ and then it applies the traditional $\mathrm{P} \& \mathrm{O}$ technique. When the algorithm oscillates near the first maximum (local or global), the actual values of voltage and power are saved. Subsequently, the reference voltage $V r$ is changed by adding a distance $d_{\text {min }}\left(V r=V r+d_{\text {min }}\right)$ and the $\mathrm{P} \& \mathrm{O}$ technique is applied again. The new maximum power point is compared to the above maximum. If the current maximum point is greater than the former, the technique starts the power search by using the current reference voltage, but if the power is lesser, the power search is performed based on the first maximum. Thus, the process is repeated for all points of the voltage-power curve, varying the initial reference voltage with integer multiples of the distance $d_{\min }$.

The minimum distance $\left(d_{\text {min }}\right)$ between each maximum point is given by equation (1), which depends on the number of panels $(n)$ and the nearest maximum voltage to the open circuit voltage $\left(V_{m p p o c}\right)$.

$$
d_{\text {min }}=\frac{V_{m p p o c}}{n}
$$

\subsection{Observe, Compare, and Perturb Method}

The Observe, Compare, and Perturb (OC\&P) method that is proposed in this paper, is a low computational cost algorithm based on the $\mathrm{P} \& \mathrm{O}$ traditional technique. It is used to track the global maximum power point in arrays of photovoltaic panels in series connection under partial shading. This iterative method avoids the prior search of local maxima conducted by the POC technique, through a comparison process executed before the application of the traditional $\mathrm{P} \& \mathrm{O}$ technique.

Firstly, the proposed algorithm performs a process of comparing the power generated by the photovoltaic generator at different reference voltages $(V r)$ in order to find the region of the curve where the global maximum power is located. Afterwards, the traditional $\mathrm{P} \& \mathrm{O}$ technique is applied, taking a starting 
point in the predetermined region. Here, the number of iterations required to track the global maximum is reduced in comparison to the POC technique, since the $\mathrm{P} \& \mathrm{O}$ technique is applied only in the region of the curve where the global maximum is found.

The selection of the reference voltages is performed by the Constant Voltage Technique. This technique is based on the assumption that the voltage of the photovoltaic panels at the maximum power point varies only slightly with the irradiance. In this way, it is supposed that the voltages of the PV array at the local maxima remain approximately constant in order to perform the previous comparison process. Figure 6 shows a flowchart of the OC\&P algorithm. This algorithm operates as follows:

1. The open circuit voltage $\left(V_{o c p}\right)$ of the solar panel is determined by using the manufacturer's datasheet. This datasheet gives the technical specifications of the panel at standard conditions of irradiance $\left(1000 \mathrm{~W} / \mathrm{m}^{2}\right)$ and temperature $\left(25^{\circ} \mathrm{C}\right)$. The value of the open circuit voltage of the photovoltaic array $\left(V_{o c p}\right)$ is estimated according to $V_{o c}=n V_{o c p}$, where $\mathrm{n}$ is the number of solar panels in series connection. A better option is to perform the measurement of the open circuit voltage $\left(V_{o c p}\right)$ of the array to initialize the algorithm.

2. The value of the maximum power point nearest to the open circuit voltage of the photovoltaic array $\left(V_{m p p o c}\right)$ is estimated. This value varies between 0.7 and 0.8 of the open-circuit voltage [21]. It can be also selected using the information on the manufacturer's datasheet.

3. The reference voltages are determined by equation (2). In this case, the variable $\mathrm{n}$ corresponds to the number of panels in series connection if there is a freewheeling diode per panel. If there is more than one freewheeling diode per panel, the variable $n$ is the number of panels multiplied by the number of freewheeling diodes in each panel according to their configuration.

$$
V_{r(i)}=\frac{i V_{m p p o c}}{n} \text { for } i=1,2, \ldots, n
$$

4. The powers delivered by the photovoltaic array for the reference voltages are determined by using the Constant Voltage Technique. For this, the duty cycle $\left(D_{i}\right)$ for each reference voltage $\left(V_{r(i)}\right)$ is applied to the SEPIC converter, following equation (3), where $V_{0}$ is the output voltage of the converter. The value of the power is determined when the stable state is reached for each reference voltage. Based on the above, if the photovoltaic array has n panels 
in series connection, it is necessary to evaluate at least $n$ points of the powervoltage curve.

$D_{i}=\frac{V_{O}}{V_{r(i)}+V_{O}}$, for $i=1,2, \ldots, n$

5. The determined powers for each reference voltage are compared and the higher power point is selected.

6. The reference voltage that corresponds to the higher power point is used as the initial point of the traditional $\mathrm{P} \& \mathrm{O}$ algorithm. In this way, the algorithm is applied and the system will converge towards the maximum global power. The algorithm is reset when a drastic change in the power occurs ( $|\mathrm{dP}|>\mathrm{dPm})$.

Figure 6. Flowchart of the OC\&P technique

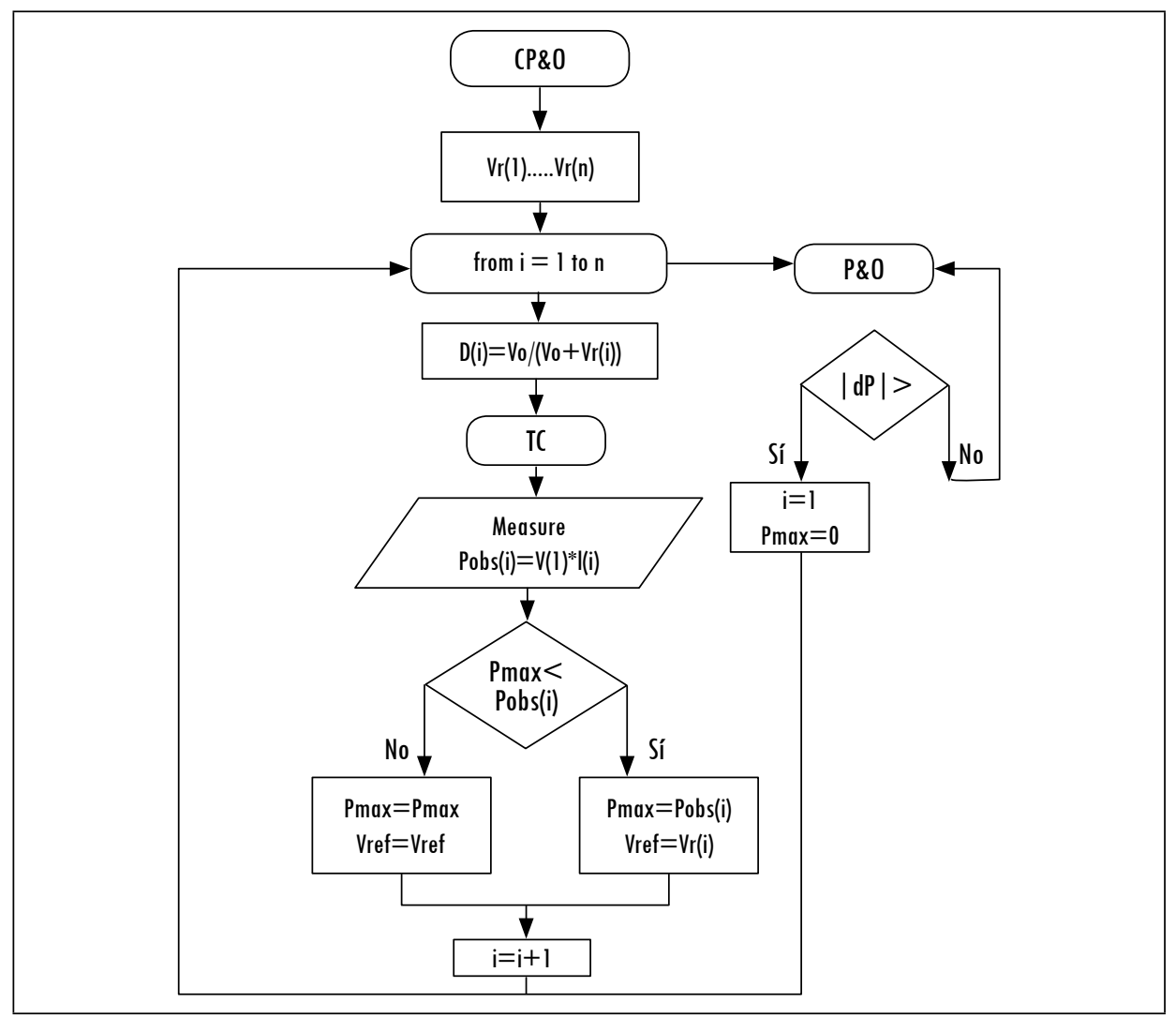

Source: Authors' own creation. 
An example of the OC\&P algorithm is presented in Figure 7. In this case, a photovoltaic array with three solar panels in series connection under partial shade is considered. As mentioned, the algorithm firstly compares three different power points and then it starts the $\mathrm{P} \& \mathrm{O}$ algorithm by using the reference voltage that corresponds to the higher power point.

Figure 7. Example of the $0 C \& P$ algorithm for an array of three solar panels under partial shading conditions

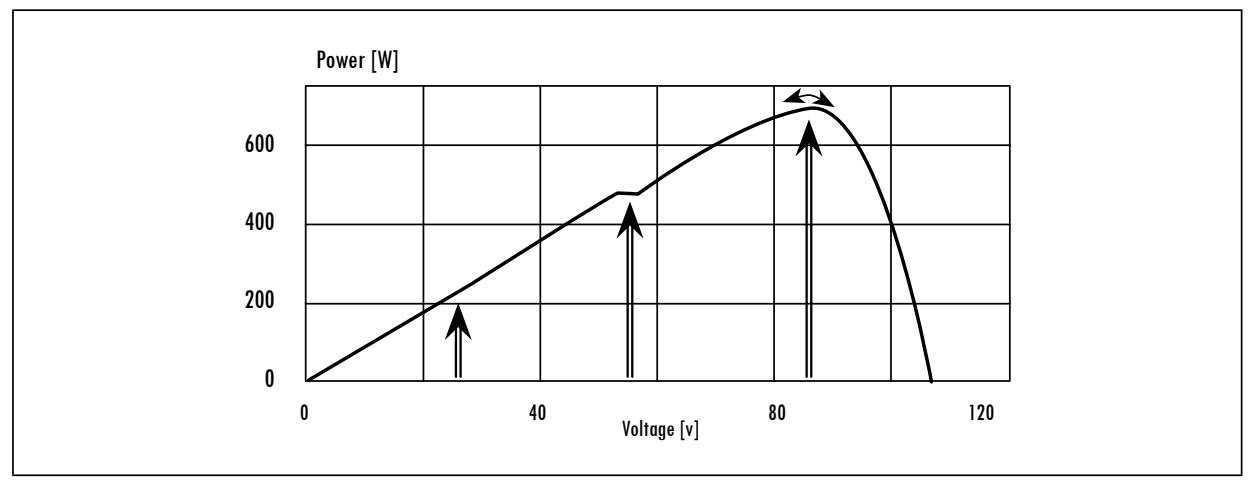

Source: authors' own elaboration

\section{Results}

In order to evaluate the performance of the proposed algorithm, simulations at the software PSIM were executed for different conditions of non-uniform irradiance and temperature in arrays of photovoltaic panels in series connection. Additionally, the operation of the proposed algorithm was compared with the operation of the traditional $\mathrm{P} \& \mathrm{O}$ technique.

The simulations were carried out for the electric circuit presented in Figure 5, which is composed of: a set of photovoltaic panels in series connection, a SEPIC converter, the control system (MPPT algorithm), and an independent voltage source $\left(V_{0}\right)$ of $460[\mathrm{~V}]$. The value of $V_{0}$ was set considering the possible connection of the system to the distribution network ( $110 \mathrm{Vrms})$ via a power inverter (see Figure 2). The simulation parameters are presented in Table 1. The inductors were sized in order to ensure the operation of the converter in continuous conduction mode, even for low values of irradiance. Additionally, in all simulation tests are considered zero initial conditions. 
Table 1. Simulation parameters.

\begin{tabular}{|l|l|}
\hline \multicolumn{1}{|c|}{ Parameter } & \multicolumn{1}{c|}{ Value } \\
\hline $\mathrm{L}_{1}=\mathrm{L}_{2}$ & $1.3 \mathrm{mH}$ \\
\hline $\mathrm{R}_{1}=\mathrm{R}_{2}$ & $0.1 \Omega$ \\
\hline $\mathrm{C}_{\text {in }=} \mathrm{C}_{1}$ & $560 \mu \mathrm{F}$ \\
\hline $\mathrm{C}_{2}$ & $1100 \mu \mathrm{F}$ \\
\hline Vo & $460 \mathrm{~V}$ \\
\hline MPPT frequency & $5 \mathrm{kHz}$ \\
\hline Switching frequency & $50 \mathrm{kHz}$ \\
\hline
\end{tabular}

Source: authors' own elaboration

\subsection{Photovoltaic Array}

These were considered photovoltaic panels reference KD240GH-2PB of KYOCERA. The electrical specifications of each panel are shown in Table 2 under standard conditions of irradiance $\left(1000 \mathrm{~W} / \mathrm{m}^{2}\right)$ and temperature $\left(25^{\circ} \mathrm{C}\right)$. The data shown in this table are provided in the manufacturer's datasheet.

Table 2. Electrical characteristics of KYOCERA panel KD240GH-2PB

at $1000 \mathrm{~W} / \mathrm{m}^{2}$ and $25^{\circ} \mathrm{C}$

\begin{tabular}{|l|l|}
\hline \multicolumn{2}{|c|}{ KD240GH-2PB of KYOCERA } \\
\hline Maximum power point & $240 \mathrm{~W}$ \\
\hline Voltage at the MPP & $29.8 \mathrm{~V}$ \\
\hline Current at the MPP & $8.06 \mathrm{~A}$ \\
\hline Open circuit voltage & $36.9 \mathrm{~V}$ \\
\hline Short circuit current & $8.59 \mathrm{~A}$ \\
\hline
\end{tabular}

Source: authors' own elaboration

\subsection{Simulation Cases}

The performance of the algorithms is evaluated in the following cases:

Case 1: It was considered a photovoltaic array with 5 solar panels of KYOCERA. The irradiance and temperature conditions for each panel are presented in Table 3, for two intervals $0 \leq \mathrm{t} \leq 1$ [s] and $1<\mathrm{t} \leq 2$ [s]. Additionally, Figures $8 \mathrm{a}$ and $8 \mathrm{~b}$ present the power-voltage curves of the resulting photovoltaic generator at the intervals $0 \leq \mathrm{t} \leq 1[\mathrm{~s}]$ and $1<\mathrm{t} \leq 2$ [s], respectively. As noted, the range of $0 \leq \mathrm{t} \leq 1[\mathrm{~s}]$ represents a high level of irradiance and temperature. In this range, 
the curve has four local maximum power points and a global maximum, which is close to the open circuit voltage. Moreover, the range of $1<\mathrm{t} \leq 2$ [s] represents conditions of low irradiance in two panels that corresponds to a partial shade in them. In this case, also four local maxima and one global maximum are presented.

Table 3. Irradiance and temperature conditions in the photovoltaic panels

\begin{tabular}{|c|c|c|c|c|c|}
\cline { 2 - 6 } \multicolumn{2}{c|}{} & \multicolumn{2}{c|}{ Case l } & \multicolumn{2}{c|}{ Case 2 } \\
\hline \multirow{3}{*}{ Intervals } & Panel & $\begin{array}{c}\text { Irradiance } \\
\left(\mathbf{W} / \mathbf{m}^{2}\right)\end{array}$ & $\begin{array}{c}\text { Temperature } \\
\left({ }^{\circ} \mathbf{C}\right)\end{array}$ & $\begin{array}{c}\text { Irradiance } \\
\left(\mathbf{W} / \mathbf{m}^{2}\right)\end{array}$ & $\begin{array}{c}\text { Temperature } \\
\left({ }^{\circ} \mathbf{C}\right)\end{array}$ \\
\hline \multirow{5}{*}{$0 \leq \mathrm{t} \leq 1[\mathrm{~s}]$} & 1 & 1100 & 40 & 350 & 15 \\
\cline { 2 - 6 } & 2 & 1050 & 39 & 300 & 12 \\
\cline { 2 - 6 } & 3 & 1000 & 35 & 250 & 11 \\
\cline { 2 - 6 } & 5 & 950 & 32 & 450 & 10 \\
\hline \multirow{5}{*}{$1<\mathrm{t} \leq 2[\mathrm{~s}]$} & 3 & 900 & 30 & 550 & 9 \\
\cline { 2 - 6 } & 2 & 500 & 40 & 350 & 12 \\
\cline { 2 - 6 } & 4 & 400 & 39 & 300 & 11 \\
\cline { 2 - 6 } & 5 & 950 & 32 & 250 & 9 \\
\hline
\end{tabular}

Source: authors' own elaboration

Figure 8. Case 1: Power-voltage curves for the generator in the intervals: a) $0 \leq t \leq 1$ [s].

b) $1<t \leq 2[s]$

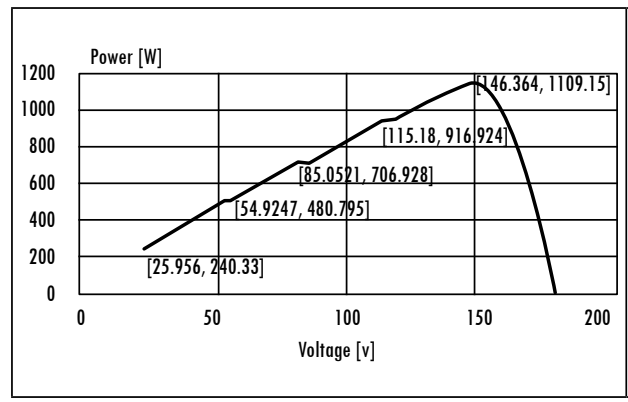

a)

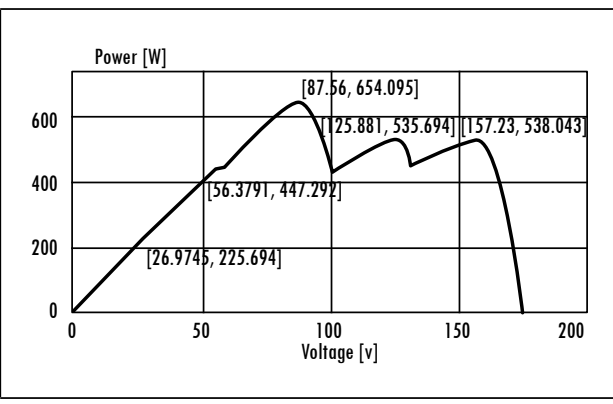

b)

Source: authors' own elaboration

Case 2: In this case, it was also considered the series connection of 5 KYOCERA panels. The irradiance and temperature conditions in each of the photovoltaic panels are presented in Table 3 , for two intervals $0 \leq \mathrm{t} \leq 1$ [s] and $1<\mathrm{t} \leq 2$ [s]. 
Additionally, Figures $9 \mathrm{a}$ and $9 \mathrm{~b}$ show the power-voltage curves for the resulting photovoltaic generator at intervals $0 \leq \mathrm{t} \leq 1[\mathrm{~s}]$ and $1<\mathrm{t} \leq 2[\mathrm{~s}]$, respectively. As seen, the range of $0 \leq \mathrm{t} \leq 1[\mathrm{~s}]$ represents low irradiance and temperature conditions in the photovoltaic panels, while the range of $1<\mathrm{t} \leq 2$ [s] represents conditions of low irradiance in three panels and high irradiance in two panels. In both intervals four local maximum and one global maximum are presented.

Figure 9. Case 2: Power-voltage curves for the generator in the intervals:

a) $0 \leq t \leq 1$ [s]. b) $1<t \leq 2[s]$

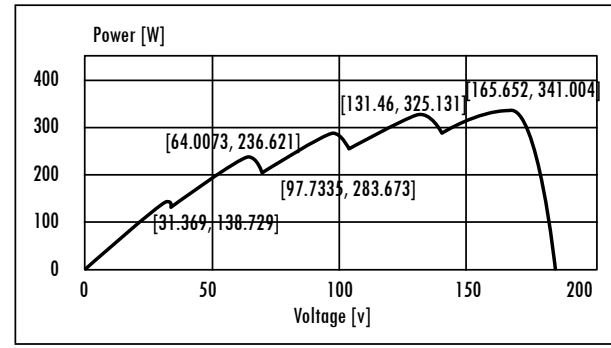

a)

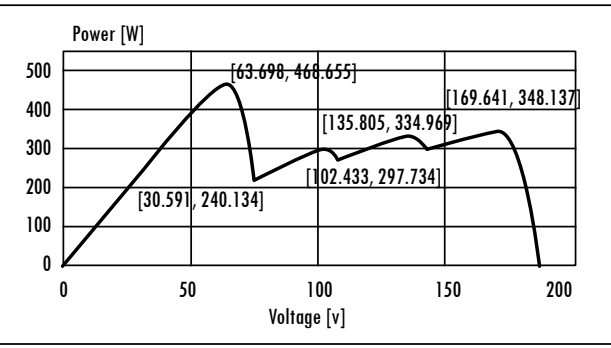

b)

Source: authors' own elaboration

\subsection{Simulation Results}

The simulation results are presented below for the two cases.

Case 1: Figures $10 \mathrm{a}$ and $10 \mathrm{~b}$ present the power generated by the photovoltaic array by using the techniques $\mathrm{OC} \& \mathrm{P}$ and $\mathrm{P} \& \mathrm{O}$, respectively. According to Figure $10 \mathrm{a}$, the algorithm OC\&P initially determines the power values for the different reference voltages (in this case 5 comparison points) and then it initializes the $\mathrm{P} \& \mathrm{O}$ technique taking as the starting point the reference voltage with the greater generated power. In this way, the OC\&P technique oscillates around the global maxima, 1109.15 W and 654.09 W (see Figure 8), for both intervals. The time required to achieve the global maximum power point corresponds to approximately $0.3 \mathrm{~s}$.

As seen in Figure 10b), the traditional $\mathrm{P} \& \mathrm{O}$ algorithm oscillates around the local maximum powers, 479.979 [W] and 447.2 [W] (see Figure 8), for both intervals. These powers correspond to the local maxima nearest to the initial point of reference used by the algorithm (initial reference voltage of 50 [V]) for the two intervals. The algorithm takes about 0.15 seconds to reach the local maximum power. 
Figure 10. Case 1: Tracking of the maximum power point using the technique: a) $0(\& P$. b) P\&O

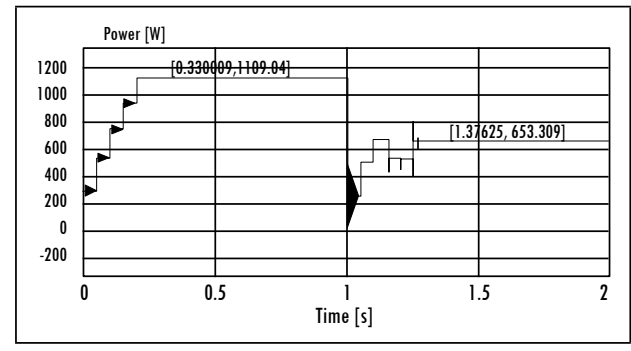

a)

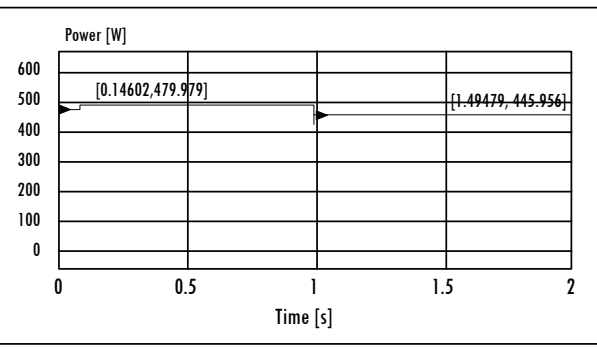

b)

Source: authors' own elaboration

Case 2: Figures $11 \mathrm{a}$ and $11 \mathrm{~b}$ show the power generated by the photovoltaic array by using $\mathrm{OC} \& \mathrm{P}$ and $\mathrm{P} \& \mathrm{O}$, respectively. In this case, the technique OC\&P oscillates around the two global maxima in steady state, 339.44 [W] and 468,199 [W] (see Figure 9) for both intervals. On the other hand, the $\mathrm{P} \& \mathrm{O}$ technique oscillates around a local maximum in the range $0 \leq \mathrm{t} \leq 1[\mathrm{~s}]$ and around the global maximum in the range $1<\mathrm{t} \leq 2[\mathrm{~s}]$, because the initial reference voltage in the second range is near to the global maximum.

Figure 11. Case 2: Tracking of the MPP using the technique: a) OC\&P. b) P\&O

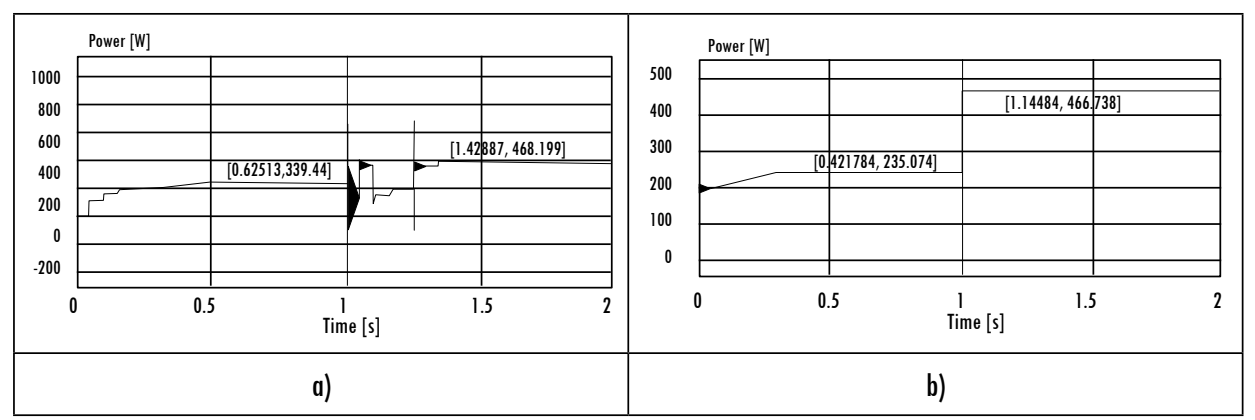

Source: authors' own elaboration

As shown in the simulation results, the point of convergence of the algorithm $\mathrm{P} \& \mathrm{O}$ depends on the initial reference voltage, so the tracking of the global maximum point is not guaranteed. This algorithm oscillates around the first maximum that is found, whether local or global. Otherwise, the OC\&P algorithm converges to the global maximum without requiring the application of $\mathrm{P} \& \mathrm{O}$ technique for each region of the curve where a maximum either local or global occurs. 


\section{Conclusions}

This article presented a new algorithm based on the classical P\&O method and the Constant Voltage technique. The proposed algorithm is used for tracking the global maximum power point of photovoltaic panels arranged in series, subject to partial shading conditions. The proposed technique executes a previous comparison process of the power generated by the photovoltaic array under different reference voltages according to the technique of Constant Voltage, in order to determine the region of the curve where the global maximum power is located. Thus, this technique avoids the convergence towards local maxima and reduces previous iterations performed by the POC technique around local maxima. This also reduces the time required to find the global maximum point.

The proposed algorithm maintains the simplicity of the traditional $\mathrm{P} \& \mathrm{O}$ algorithm, making its implementation simple. Similarly, the time required to reach the global maximum power point depends on the number of panels in series connection or the number of freewheeling diodes. This time does not depend on irradiance, temperature, or partial shading conditions in the array.

\section{References}

[1] D. Verma, S. Nema, A. M. Shandilya, and. S. K. Dash, "Maximum Power Point Tracking (MPPT) techniques: recapitulation in solar photovoltaic systems," Renew. Sust. Energ. Rev., vol. 54, no. 1, pp. 1018-1034, 2006. [Online]. Available: http://www.sciencedirect.com/ science/article/pii/S1364032115011478.

[2] B. Bendib, H. Belmili, and F. Krim, "A survey of the most used MPPT methods: conventional and advanced algorithms applied for photovoltaic systems," Renew. Sust. Energ. Rev., vol. 45, no. 1, pp. 637-648, 2015. [Online]. Available: http://www.sciencedirect. com/science/article/pii/S1364032115000970

[3] M. A. G de Brito, L. Galotto, L. P Sampaio, G. de Azevedo, and C. A. Canesin, "Evaluation of the main MPPT techniques for photovoltaics applications," IEEE Trans. Ind. Electron., vol. 60, no. 3, pp. 1156-1167, 2013. [Online]. Available: http://ieeexplore.ieee. org/stamp/stamp.jsp?tp = \&arnumber $=6196220$

[4] S. S. W. Walker, N. K. Sooriyaarachchi, N. D. B. Liyanage, P. A. G. S. Abeynayake, and S. G. Abeyratne, "Comparative analysis of speed of convergence of MPPT Techniques," in 2011 6th IEEE Int. Conf. Ind. Inf. Syst. (ICIIS), 2011, pp. 522-526. [Online]. Available: http://ieeexplore.iee.org/stamp/stamp.jsp?tp = \&arnumber $=6038125$

[5] M. A. G. de Brito, L. Galotto, L. P. Sampaio, G. de Azevedo, and C. A. Canesin, "Comparative analysis of MPPT techniques for PV applications," in 2011 Int. Conf. Clean Electr Power (ICCEP), 2011, pp. 99-104. 
[6] H. Rezk and A. M. Eltamaly, "A comprehensive comparison of different MPPT techniques for photovoltaic systems," Solar Energy, vol. 112, no. 1, pp. 1-11, 2015. [Online]. Available: http://www.sciencedirect.com/science/article/pii/S0038092X14005428

[7] M. A. Eltawil and Z. Zhao, "MPPT techniques for photovoltaic aplications," Renew. Sust. Energ. Rev., vol. 25, no. 1, pp. 1-11, 2013. [Online]. Available: http://www.sciencedirect. com/science/article/pii/S1364032113003250

[8] A. Dolara et al., "Energy comparison of seven MPPT Techniques for PV Systems," J. Electromagnet Anal. Appl., vol. 1, no. 3, pp. 152-162, 2009. [Online]. Available: http:// www.scirp.org/journal/PaperInformation.aspx?PaperID $=725$

[9] A. Al-Diab and C. Sourkounis, "Variable step size P\&O MPPT algorithm for PV systems," in 2010 12th Int. Conf. Optim. Elect. Electron. Equipment (OPTIM), 2010, pp. 1097-1102.

[10] M. A. Abdourraziq, M. Ouassaid, M. Maaroufi, "Comparative study of MPPT using variable step size for photovoltaic systems," in 2014 Second World Conference on Complex Systems (WCCS), 2014, pp. 374-379.

[11] F. A. O. Aashoor and F. V. P. Robinson, "A variable step size perturb and observe algorithm for photovoltaic maximum power point tracking," in 2012 47th Int. Univ. Power Eng. Conf. (UPEC), 2012, pp. 1-6.

[12] M. Hassani, S. Mekhilef, A. P. Hu, N. R. Watson. "A novel MPPT algorithm for load protection base on output sensing control," in 2011 IEEE Ninth Int. Conf. Power Electron. Drive Syst. (PEDS), 2011, pp. 1120-1124 [Online]. Available: http://ieeexplore.ieee.org/ stamp/stamp.jsp?tp $=$ \&arnumber $=6147400$

[13] A. Sayal, "MPPT techniques for photovoltaic system under uniform insolation and partial shading conditions," in 2012 Students Conf. Eng. Syst. (SCES), 2012, pp. 1-6.

[14] R. Alonso, P. Ibáñez, V. Martínez, E. Ramón, and A. Sanz, "An innovative perturb, observe and check algorithm for partially shaded PV systems," in 13th Eur. Conf. Power Electron. Appl., 2009, pp. 1-8.

[15] E. Durán, M. Sidrach, J. Galán, and J. M. Andujar, "Comparative analysis of buck-boost converters used to obtain I-V characteristic curves of photovoltaic modules," in IEEE Power Electron. Specialist Conf., 2008, pp. 2036-2042.

[16] S. J. Chiang, H. Shieh, and M. Chen, "Modeling and control of PV charger system with SEPIC converter," IEEE Trans. Ind. Electron., vol. 56, no. 11, pp. 4344-4353, 2009. [Online]. Available: http://ieeexplore.ieee.org/stamp/stamp.jsp?tp $=$ \&arnumber $=4631374$

[17] M. Marodkar, S. Adhau, M. Sabley, and P. Adhau, "Desing and simulation of DC-DC converters for photovoltaic system based on Matlab," in 2015 Int. Conf. Ind. Instru. Control (ICIC), 2015, pp. 1478-1483.

[18] M. Killi and S. Samanta, "Output voltage sensor based maximum power point tracking for PV system using SEPIC," in 2015 IEEE Int. Conf. Ind. Technol. (ICIT), 2015, pp. $1112-$ 1116. 
[19] R. F. Coelho et al., "Analytical and experimental analysis of DC-DC converters in photovoltaic maximum power point tracking applications," in 36th Ann. Conf. on IEEE Ind. Electron. Soc. (IECON(, 2010, pp. 2778-2783.

[20] J. J. Nedumgatt et al., "Perturb and observe MPPT algorithm for solar PV systems -modeling and simulation," in 2011 Ann. IEEE India Conf. (INDICON), 2011, pp. 1-6.

[21] L. Hassaine, "Implementación de un control digital de potencia activa y reactiva para inversores: aplicación de sistemas fotovoltaicos conectados a la red," Ph.D. dissertation, Departamento de Tecnología Electrónica, Universidad Carlos III de Madrid, Leganés, España, 2010. 
